\title{
OPEN Author Correction: The balance of metagenomic elements shapes the skin microbiome in acne and health
}

\author{
Emma Barnard, Baochen Shi, Dezhi Kang, Noah Craft \& Huiying Li \\ Correction to: Scientific Reports https://doi.org/10.1038/srep39491, published online 21 December 2016
}

The Article contains an error in the Data Availability section, where the accession code is missing the BioProject prefix "PRJNA". The correct accession is PRJNA283427. As such, this section should read:

Data Availability

The sequence data from this study have been submitted to NCBI BioProject (http://www.ncbi.nlm.nih.gov/bioproject) under BioProject number PRJNA283427.

(c) (i) Open Access This article is licensed under a Creative Commons Attribution 4.0 International License, which permits use, sharing, adaptation, distribution and reproduction in any medium or format, as long as you give appropriate credit to the original author(s) and the source, provide a link to the Creative Commons license, and indicate if changes were made. The images or other third party material in this article are included in the article's Creative Commons license, unless indicated otherwise in a credit line to the material. If material is not included in the article's Creative Commons license and your intended use is not permitted by statutory regulation or exceeds the permitted use, you will need to obtain permission directly from the copyright holder. To view a copy of this license, visit http://creativecommons.org/licenses/by/4.0/.

(C) The Author(s) 2020 